\title{
Construction and Characterization of a Small-Bore Electrospray Ionization Source
}

\author{
Norman Sproch and Terry Kruger \\ Department of Chemistry, Ball State University, Muncie, Indiana, USA
}

\begin{abstract}
A simple, economical, and efficient electrospray ionization (ESI) source has been constructed in the configuration of a probe that makes use of a standard $13 \mathrm{~mm}$ vacuum lock. The principal components have been placed inside a glass tube making use of the electrical insulating properties of the glass while allowing for visual adjustments to be readily made. The ESI source, a variation of an atmospheric pressure ionization interface, is a modified version of designs published by Chait et al. (Rapid Comm. Mass Spectrom. 1990, 4, 81-87) and Knapp et al. (Anal. Chem. 1991, 63, 1658-1660) wherein a heated metal capillary is used for desolvation. The ESI probe has been tested on three different Extrel quadrupole mass spectrometers, with removable ion volumes, using polypeptides and small proteins. No modifications to the standard electron ionization/chemical ionization lens assembly were required to obtain excellent results other than removal of the ion volume. The spectra acquired were in excellent agreement with those previously published. (J Am Soc Mass Spectrom 1993, 4, 964-967)
\end{abstract}

$\mathrm{H}$ ere we report the construction of a glass tube (13-mm diameter) encased electrospray ionization (ESI) source capable of introducing protein ion containing aerosols directly into the urmudified electron ionization/chemical ionization (EI/CI) lens assembly of a quadrupole mass spectrometer ( $\mathrm{Ex}$ trel ELQ 400, Millipore/Extrel, Pittsburgh, PA). This ESI source has been designed as a removable probe assembly and is therefore conveniently referred to as an ESI probe in this article. The ESI probe design is a modified version of ESI source designs published by Chait et al. [1] and Knapp et al. [2] using a heated metal capillary for desolvation. The ESI probe features a brass skimmer cone and threaded capillary tube resting in a threaded brass spacer, which were machined locally. This design allows easy and reproducible adjustment between the tube and skimmer. All ESI probe components are concentric with the lens and quadrupole analyzer. The positioning of the probe may follow either of two patterns: just in front of the repeller contacts for the removable ion volume with the standard 400 series EI/CI lens assembly or, $\sim 0.5-1.0 \mathrm{~cm}$ from the first lens in the lens stack.

The ability to switch between EI/CI and ESI by simply removing the ion volume and inserting the ESI probe (10-15 minutes) without physically rcconfiguring the instrument adds greatly to the versatility of this design. The $13-\mathrm{mm}$ probe diameter facilitates the use of ESI experiments on any instrument with a

Address reprint requests to Dr. Terry Kruger, Department of Chemistry, Ball State University, Muncie, IN 47306. 13-mm (or one-half inch) vacuum lock coaxial to the lens assembly. The ESI probe was also used with a modified fast-atom bombardment (FAB) lens stack consisting of three lenses. The size of the probe, cunvenience of its use, ready availability of its components, ease of adjustment of its dimensions, demonstrated high ion currents with or without modification of the remaining structure of the source and ease with which it can be maintained and modified each contribute to the utility of the design.

This design may be considered a variation of the atmospheric pressure ionization (API) interface, specialized for sampling polypeptides. API interfaces with other design objectives have been reported elsewhere [3].

\section{Experimental}

The drawing for the electrospray probe (overall length, $44 \mathrm{~cm}$ ) is shown in Figure 1. The syringe (not shown) emitting the aerosol is colinear with and $\sim 0.5 \mathrm{~cm}$ to the left of the capiliary tube conducting the sample into the mass spectrometer (Figure 1). The right portion of the probe $(30-35 \mathrm{~cm})$ is inserted through the front gate valve, which in other experiments is used to insert an ion volume. The aerosol originates from a blunt needle (Hamilton 80426, 25 gauge, \#3 point) fitted to a Hamilton \#701 (Reno, NV) $10 \mu \mathrm{L}$ syringe using a flowrate of $2 \mu \mathrm{L} / \mathrm{min}$ of $3-7 \times 10^{-5} \mathrm{M}$ solution of protein. The syringe pump is of one of the authors ${ }^{\prime}$ design and was built in our lab. The syringe needle is maintained at a potential of $\sim 4000$ volts, 


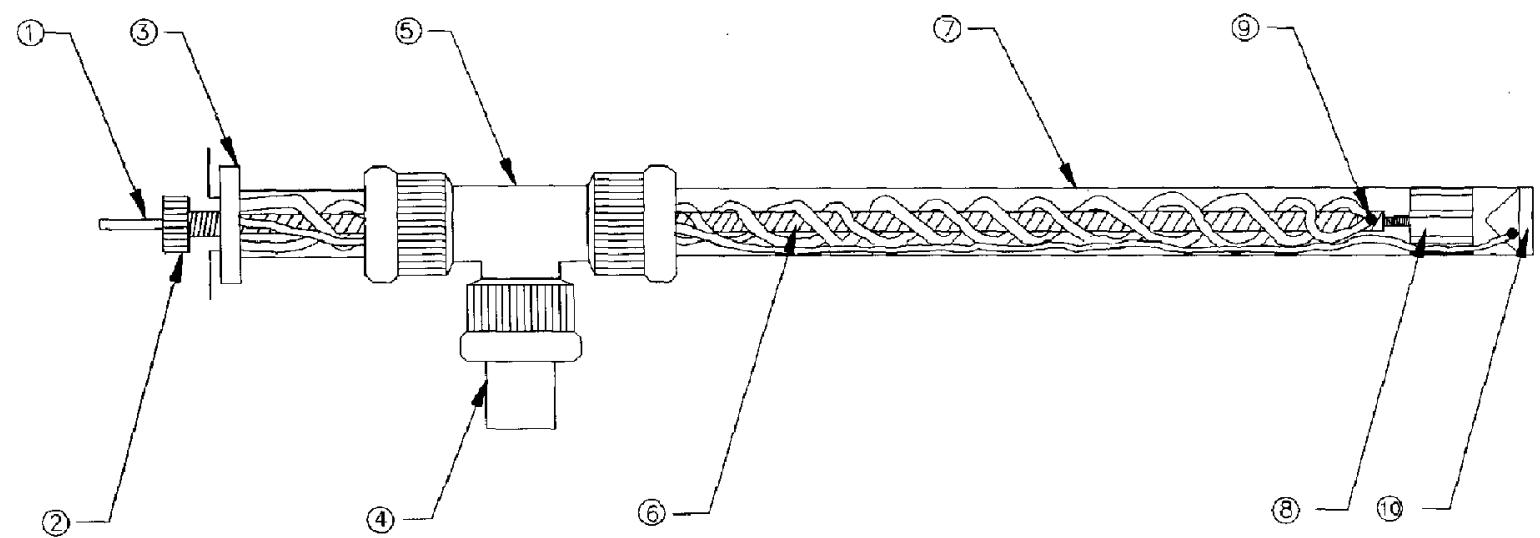

Figure 1. Schematic of the ESI source/probe (overall length, $44 \mathrm{~cm})$; (1) capillary tube, $(43 \mathrm{~cm})$; (2) Knurl-Lok I fitting; (3) endcap with wire feedthroughs; (4) roughing pump connection; (5) Cajon Ultra-Torr Tee; (6) nichrome heater; (7) 13-mm diameter glass housing; (8) threaded brass spacer for the capillary tube; (9) iron-constantan thermocouple; (10) brass skimmer cone.

direct current (VDC). The stainless-steel capillary (50 $\mathrm{cm}$, Upchurch Scientific, Oak Harbor, WA) is maintained at a potential of $170 \mathrm{VDC}$. As pictured in Figure 1 , one end of the capillary is threaded into the brass spacer until flush at the inner face. The inner surface of the brass spacer is $\sim 3 \mathrm{~mm}$ from the entrance to the brass skimmer cone, which has an orifice of $0.5 \mathrm{~mm}$. The ESI source is evacuated through a $13-\mathrm{mm}$ glass tube joined to the probe by means of a stainless stecl Cajon Ultra-Torr Tee ( $1 / 2$, SS-8-UT-3, Cajon Company, Macedonia, OH). A pumping capacity of $834 \mathrm{~L} / \mathrm{min}(2$ Edwards 18's@ $417 \mathrm{~L} / \mathrm{min}$ each) was adequate for efficient operation. External electrical connections at the probe provided for application of $170 \mathrm{VDC}$ on the capillary, 58 VDC on the skimmer, and heating of the $43-\mathrm{cm}$ capillary tube to $95^{\circ} \mathrm{C}$ using a Variac as the alternating current (AC) source (typically $10 \mathrm{VAC}$ ). The high vollage, capillary, and skimmer voltages were referenced to and used a common ground. This was isolated from the instrument ground to reduce interference from occasional high voltage arcing. The heater coil was made from $0.5-\mathrm{mm}$ diameter nichrome wire, which was wound around the capillary and was insulated, as were all internal probe wires, with fiberglass sleeving (Omega Engineering, Stamford, CT, NI80-02050, AWG 24, and FBGS-N-24). An iron-constantan thermocouple (Scientific Instrument Services, Ringoes, NJ, TH-4) was used for temperature measurement with a Keithley (Cleveland, OH) 150B microvolt meter. The high voltage was provided by an Antek (Palo Alto, CA) PS-4 series power supply used by Extrel for the FAB accessory, and two identical Heathkit (Benton Harbor, MI) IP-17 regulated power supplies provided the two other $D C$ voltages. The power supply voltages were monitored with Simpson 260 (analog) and 460 (digital) multimeters. The probe endcap with wire feedthroughs and the skimmer cone were sealed to the glass housing by using Apiezon W (Apiezon Products, UK) vacuum wax initially and in the most recent version with Devcon 5-Minute epoxy (Devcon Corp., Danvers, MA). The stainless-steel endcap was machined locally and a stainless-steel Knurl-Lok I fitting with a PEEK ferrule (Alltech Associates, Inc., Deerfield, IL) for the capillary tube was machined and pressed into the endcap. The pressure in the line leading from the mechanical pumps to the probe tee, which was measured using a Hastings gauge, was found to be $\sim 1$ torr. The pressure in the source and analyzer manifolds were monitored by using ion gauge tubes giving typical values, respectively, of $1.5 \times 10^{-4}$ and $1.5 \times 10^{-5}$ torr. The capillary-to-skimmer gap may be adjusted to maintain pressure in the analyzer at $10^{-5}$ torr.

At Virginia Commonwealth University slightly different configurations were used with the two mass spectrometers. A Sage Instruments (Boston, MA) syringe pump (model \#341A) was used, while pumping was provided by a $27 \mathrm{ft}^{3} / \mathrm{min}$ (Alcatel model \#1201080401) roughing pump. A Phrasor Scientific Inc. (Duarte, CA) high voltage power supply and Brandenburg (England) DC power supply were used. The single quadrupole instrument had a custom lens stack while the dual mass spectrometer had a standard Extrel EI/CI 400 series (Millipore/Extrel, Pittsburgh, PA) lens assembly.

Three Extrel quadrupole mass spectrometers were used to characterize the source. Two single quadrupole instruments and one custom double quadrupole instrument [4] were used. Two different data systems were used for data acquisition. Extrel's Ionstation software (Ver. 2.0) on a Sun Sparcstation II was used with our Extrel 400 and the other, a Teknivent (Maryland Heights, MO) Vector Two on a custom Extrel single and 90 degree Extrel 400 dual quadrupole at Virginia Commonwealth University.

The following polypeptides were used to optimize the ESI source. Angiotension III (Sigma \#A-0903, 30 pmol $/ \mu \mathrm{L}$ ), bradykinin (Sigma \#B-3259, $47 \mathrm{pmol} / \mu \mathrm{L}$ ), 
renin substrate (Sigma \#R-8380, $56 \mathrm{pmol} / \mu \mathrm{L}$ ), melittin (Sigma \#M-2272, $50 \mathrm{pmol} / \mu \mathrm{L}$ ), glucagon (Figure 2, Sigma \#G-1774, $50 \mathrm{pmol} / \mu \mathrm{L}$ ) were prepared with equal parts of methanol and $1 \%$ acetic acid/water. Cytochrome $c$ (Figure 3, horse heart, Sigma \#C-2506, $67 \mathrm{pmol} / \mu \mathrm{L}$ ) was prepared with $2 \%$ acetic acid/water and methanol.

Interface cleaning is accomplished with the probe removed by using three strategies. The capillary tube and skimmer opening may be reamed with 360 micron O.D. fused silica capillary tubing. Alternately, the fused silica capillary tubing may be connected to highperformance liquid chromatography pumps which then flush the stainless-steel capillary tube and skimmer cone with an appropriate solvent $\left(\mathrm{MeOH} / \mathrm{H}_{2} \mathrm{O}\right.$, dichloromethane). Finally, the inside of the probe may be washed by filling the probe with a solvent at the roughing pump connection and rinsing.

\section{Results and Discussion}

The data collected on the three different instruments gave similar results which were quite comparable in turn with previously published results $[1,5,6]$. While no attempt was made to maximize the sensitivity of the system, as little as 8 seconds of accumulated scans, at $400 \mathrm{u} / \mathrm{s}$ covering a mass range of $1550 \mathrm{u}$, was found to produce a characteristic spectrum. The spectra of glucagon and cytochrome $c$ are shown in Figures 2 and 3 , respectively. The relative intensity differences within the envelope of peaks as compared to other published data may be attributed to different concentrations of acid or to slight differences in operating conditions. The change in acid concentration causes a shift of the multiply protonated molecular ion envelope, increased acid concentration showing more highly protonated species. Spectra obtained with our probe

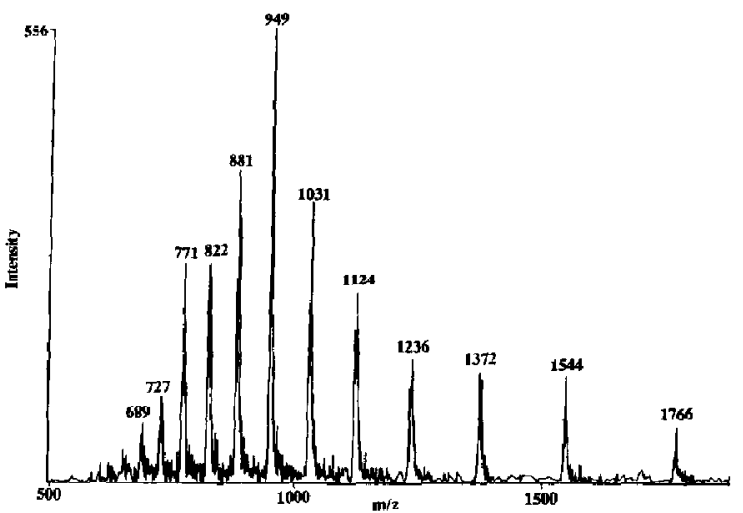

Figure 3. ESI spectrum of cytochrome $c$ (horse heart) using an Extrel ELQ 400 single quadrupole mass spectrometer (67 pmol $/ \mu \mathrm{L}$ in 50:50 MeOH: $\mathrm{H}_{2} \mathrm{O}, 2 \%$ acetic acid infused at 2 $\mu \mathrm{L} /$ min). The spectrum was acquired with an Extrel/Sun Ionstation data system scanning at $333 \mathrm{u} / \mathrm{s}$ between a mass range of 450 to 2000 u over a 1.88 minute period, electron multiplier at $-1800 \mathrm{VDC}$.

were compared with spectra from an ESI source similar in design to that described by Knapp et al. [2] and built at Virginia Commonwealth University in Wysocki's lab [7]. Glucagon (Figure 2, $3483 \mathrm{Da}$ ) was characterized by two predominant peaks, the $+4(\mathrm{~m} / \mathrm{z}$ $872)$ and the $+3(\mathrm{~m} / z$ 1162) multiply protonated molecular ions. This is representative of other reported spectra [6], the small peaks were not identified. Cytochrome $c(12,360$ Da [4]) was characterized by an envelope of ions representing a range of charge states from 7 to 20 with the most intense peak at $+13(\mathrm{~m} / \mathrm{z}$ 949). The spectrum compares favorably with the envelope of peaks reported by Chait [1] and others [5, 6]. Comparisons were obtained on both single and dual quadrupole instruments, with few differences seen in spectra or total ion count.
Figure 2. ESI spectrum of glucagon using a standard $\mathrm{EI} / \mathrm{CI}$ lens assembly on an Extrel dual quadrupole mass spectrometer [5] $(50 \mathrm{pmol} / \mu \mathrm{L}$ in $50: 50$ $\mathrm{MeOH}: \mathrm{H}_{2} \mathrm{O}, 1 \%$ acetic acid infused at 2

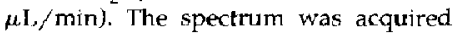
with a Teknivent (Maryland Heights, MD) Vector Two data system scanning at $72 \mathrm{u} / \mathrm{s}$, between a mass range of 500 to 1900 u over a 6.60 minute period, electron multiplier at -1800 VDC.

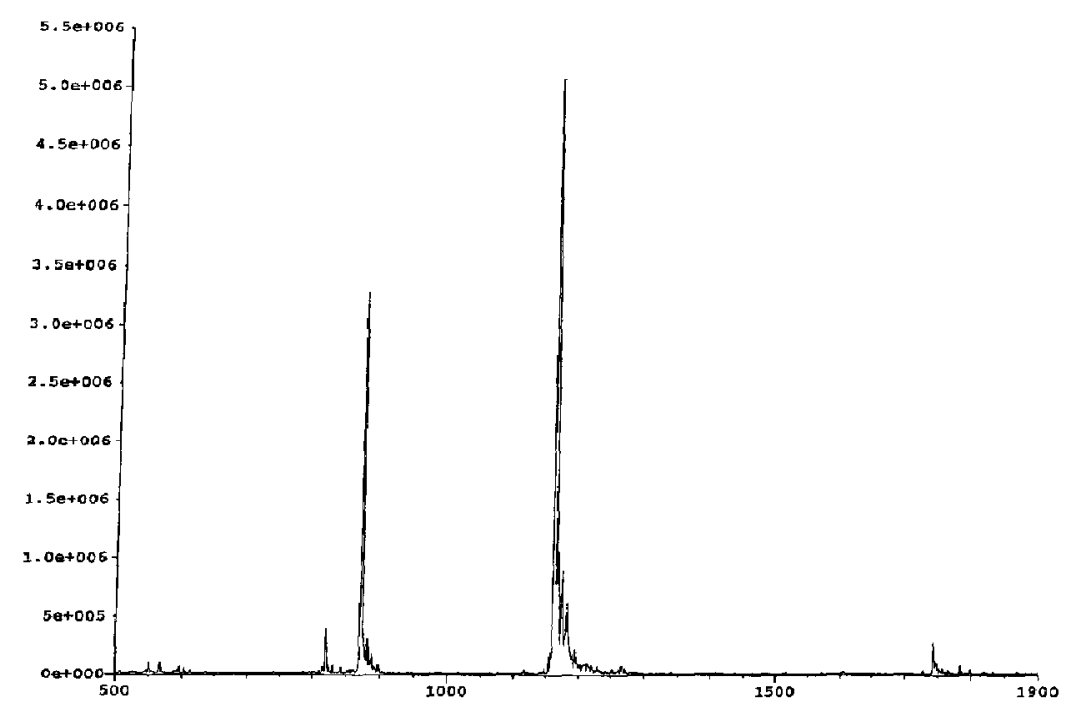




\section{Conclusion}

An economical ESI source designed as a probe capable of insertion into a standard 13-mm (one-half inch) vacuum lock has been shown to produce the same spectra as those produced with other electrospray sources. The heated capillary, originally of Chait et al. [1] is maintained in this new design. The probe construction of assembled components in a glass tube reduces the volume so that a $13-\mathrm{mm}$ vacuum lock may be accommodated. The decreased radius required increased pumping capacity on the probe. The demonstrated ability to use this ESI probe with a standard configuration EI/CI lens assembly has obvious advantages. The extremely economical construction should encourage further development of this design.

\section{Acknowledgments}

We thank the Ball State University Major Equipment Fund. We thank Dr. Vicki Wysocki and Jennifer Jones of Virginia Commonwealth University, Richmond, Virginia, for advice in construction and allowing us to use their mass spectrometers to characterize our ESI probe. We thank the number of people at Extrel who have assisted in answering questions and providing information. We also thank Randall and Nathan Morris at R\& N Machine \& Tool, Inc., Farmland, Indiana, for their expert machine work.

\section{References}

1. Chait, B. T.; Katta, V.; Chowdhury, S. K. Rapid Comm. Mass Spectrom. 1990, 4, 81-87.

2. Knapp, D. R.; Schey, K. L.; Papac, D. I. Anal. Chem, 1991, 63, $1658-1660$.

3. Duffin, K.; Wachs, T.; Henion, J. Proceedings of the 38th Anrual ASMS Conference on Mass Spectrometry and Allied Topics; Tucson, $\Lambda Z, 1990$; pp 1212-1213.

4. Wysocki, V. H.; Ding, J.-M; Jones, J. L.; Callahan, J. H.; King, F. L. J. Am. Soc. Mass Spectrom. 1992, 3, 27-32.

5. Udseth, H. R.; Barinaga, C. J.; Edmonds, C. G.; Loo, J. A.; Smith, R. D. Anal. Chem. 1990, 62, 882-899.

6. Edmonds, C. G.; Smith, R. D. Methods in Enzymology 1990, 193, $412-431$.

7. McCormack, A. L.; Jones, J. L.; Wysocki, V. H. J. Am. Soc. Mass Spectrom. 1992, 3, 859-862. 